\title{
BM] Global Health The How Project: understanding contextual challenges to global surgical care provision in low-resource settings
}

\author{
Nakul P Raykar, ${ }^{1,2,4}$ Rachel R Yorlets, ${ }^{3}$ Charles Liu, ${ }^{1,4}$ Roberta Goldman, ${ }^{5,6}$ \\ Sarah L M Greenberg, ${ }^{1,7}$ Meera Kotagal, ${ }^{1,8}$ Paul E Farmer, ${ }^{1,4,9,10}$ \\ John G Meara, ${ }^{1,3,4}$ Nobhojit Roy, ${ }^{11,12}$ Rowan D Gillies ${ }^{1}$
}

To cite: Raykar NP,

Yorlets RR, Liu C, et al. The How Project: understanding contextual challenges to global surgical care provision in low-resource settings. BMJ Global Health 2016;1: e000075. doi:10.1136/ bmjgh-2016-000075

Nobhojit Roy and Rowan D Gillies are co-senior authors.

Received 26 April 2016 Revised 14 October 2016 Accepted 11 November 2016

CrossMark

For numbered affiliations see end of article.

Correspondence to

Dr Nakul P Raykar;

nraykar@bidmc.harvard.edu

\section{ABSTRACT}

Introduction: 5 billion people around the world do not have access to safe, affordable, timely surgical care. This series of qualitative interviews was launched by The Lancet Commission on Global Surgery (LCoGS) with the aim of understanding the contextual challenges - the specific circumstances-faced by surgical care providers in low-resource settings who care for impoverished patients, and how those providers overcome these challenges.

Methods: From January 2014 to February 2015, 20 LCoGS collaborators conducted semistructured interviews with 148 surgical providers in low-resource settings in 21 countries. Stratified purposive sampling was used to include both rural and urban providers, and reputational case selection identified individuals. Interviewers were trained with an implementation manual. Following immersion into de-identified texts from completed interviews, topical coding and further analysis of coded texts was completed by an independent analyst with periodic validation from a second analyst.

Results: Providers described substantial financial, geographic and cultural barriers to patient access. Rural surgical teams reported a lack of a trained workforce and insufficient infrastructure, equipment, supplies and banked blood. Urban providers face overcrowding, exacerbated by minimal clinical and administrative support, and limited interhospital care coordination. Many providers across contexts identified national health policies that do not reflect the realities of resource-poor settings. Some findings were region-specific, such as weak patient-provider relationships and unreliable supply chains. In all settings, surgical teams have created workarounds to deliver care despite the challenges.

Discussion: While some differences exist between countries, the barriers to safe surgery and anaesthesia are overall consistent and resource-dependent. Efforts to advance and expand global surgery must address these commonalities, while local policymakers can tailor responses to key contextual differences.

\section{INTRODUCTION}

About one-third of the global disease burden is surgical, ${ }^{1}{ }^{2}$ yet five billion people around the world do not have access to safe, timely, affordable surgery. ${ }^{23}$ The Lancet Commission

\section{Key questions}

What is already known about this topic?

- There has been a paradigm shift in the perception of the role of surgical care within health systems. Formerly called the 'neglected stepchild' of global health, surgery is now recognised as an 'indivisible, indispensable part of healthcare', and is the focus of three recent policy and research documents from major institutions and organisations: the World Bank's Disease Control Priorities-3 (DCP-3) to The Lancet Commission on Global Surgery (LCoGS) and the WHO. In summary, in order to meet the needs of the five billion people who lack access to surgical care, operative volume will need to increase by at least 143 million procedures per year, and the world will need millions of additional surgeons, anaesthetists and obstetricians. Universal health coverage schemes could cover essential surgery for $\$ 3$ billion for a cost-benefit ratio of 1:10.

What are the new findings?

- While attention may have shifted towards surgical systems, and much-needed effort has gone into detailing the scope of deficits based on large, global data sets, less attention has been paid to short-term and medium-term solutions that can be implemented immediately at minimal cost. Given the global scale of this work, few have the expertise that transcends borders, cultures and contexts to be able to meaningfully describe the challenges faced by providers in the world's poorest areas and highlight relevant solutions for each. The authors and our collaborators interviewed a variety of providers in 21 countries across both urban and rural settings. As we note in the manuscript's discussion, these providers actively battle the challenges associated with weak health systems on a daily basis, and heroically provide care despite difficult settings and trying circumstances. Many of these providers do not speak English. Some are the sole providers of care within a catchment area that extends hundreds of kilometres. Despite having the best understanding of the challenges in low-resource care provision, these individuals are typically left out of the published literature and global initiatives. This manuscript represents the voices of providers on the front line of surgical care delivery worldwide. 


\section{Key questions}

\section{Recommendations for policy}

- Urgent and immediate attention is required to make safe, affordable and timely surgical care available to the billions currently without it. In an era where surgical care is increasingly recognised as a critical tool in the public health armament, a thorough understanding of local context is essential to inform viable implementation strategies. After all, time and time again, public health interventions that lack understanding of the local context have failed in implementation. This manuscript highlights the challenges viewed from the front line of surgical care provision to impoverished patients in the world's lowest resource areas, as well as potential workarounds from the providers who practise in these settings; few studies have explored this. Many implementation lessons are to be learnt from their collective experience.

on Global Surgery started in January 2014 when clinicians, researchers and policymakers from around the world met in Boston to assess the global state of surgical care, and to develop recommendations for its improvement. A working group was convened to address the key challenges in global surgical care delivery and management. It is evident from the published literature, mostly from academic institutions in high-income countries, that there are major deficits in nearly every domain of surgical care delivery, and there is broad consensus that the aetiology of these deficits is multifactorial, including insufficient infrastructure, ${ }^{4}$ workforce shortages ${ }^{5}{ }^{6}$ and limited financing. ${ }^{7}$

As the conversation shifted from defining the problem to recommending solutions, it became clear that the available data were broad but lacked the necessary depth to prioritise action across contexts. Furthermore, little existing literature captured the voice of front-line surgical practitioners in low-resource settings. As such, the Commission launched a global qualitative data collection initiative to learn the perspective of front-line providers regarding the challenges of surgical care provision in low-resource settings, and how they manage to deliver care despite those obstacles. Accordingly, this effort was titled 'The How Project'.

\section{METHODS}

\section{Study design and interviews}

A semistructured interview guide ${ }^{8}$ was developed to cover challenges and workarounds in the areas of patient access, in-hospital surgical care delivery, and policies and regulations. The interview guide was piloted in South Asia and underwent multiple adjustments prior to finalisation, in accordance with standard qualitative interview methodology. An interview implementation manual was then developed to train future interviewers during a $45 \mathrm{~min}$ training session, either in person or via a video call. Interviewers used spontaneous follow-up questions and probes. ${ }^{9}$ Interviewers made field notes during or after each interview, and some used audio recordings and transcription software to supplement these notes. ${ }^{8}$ Interviews were conducted in person, by phone or a video call, and lasted from 30 to $60 \mathrm{~min}$. In order to hear local providers' perspectives, it was important to have local collaborators conduct the interviews in their respective settings and, as a result, implementation varied to some extent.

Reputational case selection was used to identify and invite surgical providers in each country to participate in a qualitative interview based on contacts and affiliations from the Commission, in settings where contacts had capacity and interest in conducting interviews, ${ }^{10}$ and stratified purposive sampling was used to include rural and urban settings. Participants were contacted by email, phone or in-person conversation, and informed that responses would be de-identified and that no compensation would be provided. From January 2014 to February 2015, 20 interviewers conducted semistructured interviews with 148 providers in low-resource settings in 21 countries (figure 1A-C).

\section{Analysis}

All interview notes, and transcripts, when available, were translated into English by research team members who are native speakers of the respective languages. Any identifiers (eg, participants' names, facility names, country names) were removed by the data analysts to preserve anonymity. For the first set of completed interviews (15 from one country), two authors read the interview notes multiple times to identify salient topics and themes and to develop a code manual for coding subsequent interviews. ${ }^{11}$ One of the analysts completed the analysis for the remaining interviews, modifying the coding manual as necessary, and discussing new topics with the second analyst. The primary analyst has a background in public health and has been working on global surgical public health for several years. The secondary analyst has a background in surgery and has worked clinically and in a research capacity in several countries. Data were manually coded in Microsoft Word, organised into the coding manual in Microsoft Excel, summarised for each country, and stratified by urban versus rural facilities. ${ }^{11}$ Interviewers were given a summary of their data, and the opportunity to provide feedback.

\section{RESULTS}

A total of 148 providers in rural (49\%) and urban (51\%) low-resource settings in 21 countries were interviewed by 20 interviewers (figure $1 \mathrm{~A}-\mathrm{C}$ ). Despite variation in the local context, several common themes emerged related to provision of surgical care. The most common themes are presented with selected data in the form of field notes and direct quotations. When quotes are attributed to providers from specific global burden of disease regions of the world, ${ }^{12}$ it does not imply that these examples are exclusive to only those regions of the world. In fact, on the contrary, the authors have attempted to include concepts that are common across regions. 

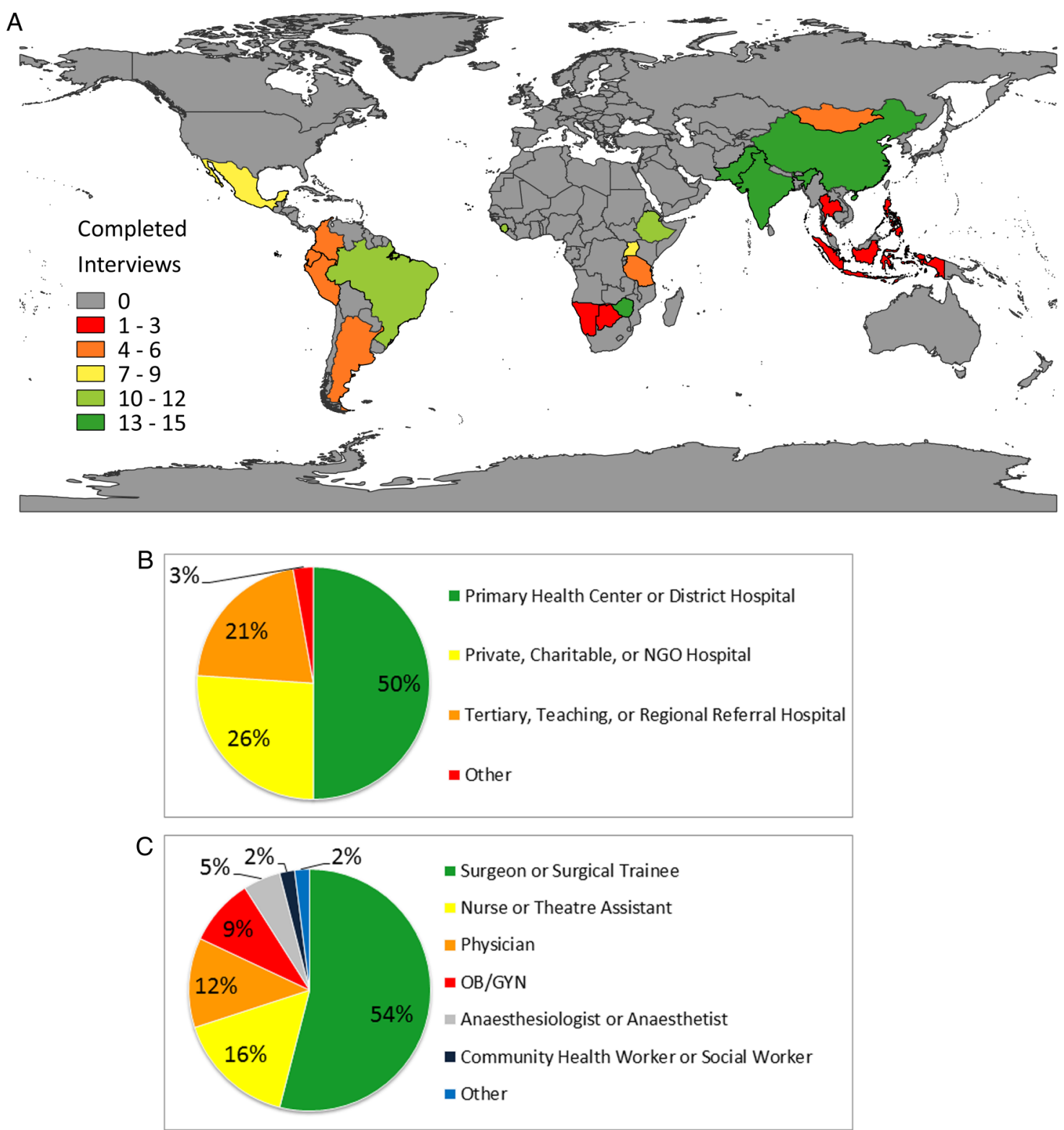

Figure 1 (A) Distribution of interviews conducted in each of the 21 countries. (B) Types of facilities where participants practice. (C) Occupations of participants. NGO, non-governmental organisation; OB/GYN, obstetrics/gynaecology.

\section{THEME 1: POVERTY INFLUENCES ALL ASPECTS OF PATIENT ACCESS}

Providers reported that poverty limits access to care most directly through hospital fees. They noted that their patients are frequently required to pay for treatment on arrival at the hospital, even in countries where universal health coverage systems exist (Eastern sub-Saharan Africa, South Asia, Western sub-Saharan Africa). In most of the settings included in this study, patients are also required to purchase their own supplies, medications and blood.

If someone has to pay more than 500-600 rupees (about US $\$ 10)$, you are pushing them into poverty.

Quote, South Asia

It's true that poverty goes hand-in-hand with disease.

Quote, Eastern sub-Saharan Africa
It's very difficult when you want to help someone, but you can't because they can't pay.

Quote, Eastern sub-Saharan Africa

The direct costs of care, however, are only a small facet of the poverty-related challenges that limit access to surgery. Providers note that the scarcity of surgical facilities forces patients to travel great distances, as far as $250 \mathrm{~km}$ (Eastern sub-Saharan Africa), to reach care. Some areas are so remote, note providers, that patients would require a helicopter (Tropical Latin America) or plane (Central Asia, Southeast Asia) to reach the hospital within any reasonable time frame. Instead, patients and their families travel by foot, bicycle (Western sub-Saharan Africa), rickshaw (South Asia, Southeast 
Asia), ox-cart or decrepit public transportation, are subject to the whims of seasonal road conditions, and will require food and lodging for multiple days away from home. One rural provider explained that patients from tribal villages must walk $10 \mathrm{~km}$ to a bus stop before up to three bus transfers over hilly roads just to get to the hospital (South Asia). Even patients who live in the same city as a surgical hospital often cannot afford the multihour trip using public transportation or other modalities (Central Latin America, South Asia). If transfer to another medical facility is required after reaching the hospital, these costs will also fall on patients. The result, as one rural provider articulated, is that it is difficult to get patients to 'make the trip for anything that is less than the most urgent' (South Asia).

If patients come to the hospital and they can't get treated, they already spent the money equivalent to a week's worth of food just to get there. Sons and daughters must take time off work. The whole family comes to see the patient.

Field Note, Central Latin America

The challenges of chronic poverty add another layer of complexity for patients needing surgery. Cultural beliefs and a general mistrust of healthcare, informed by years of limited interaction and poor experience with the formal education and health systems, can play a strong role in keeping patients away from the hospital (Andean Latin America, East Asia, Eastern sub-Saharan Africa, South Asia, Southern sub-Saharan Africa).

Some have the tendency to think that the surgical needs they have will disappear by praying, by just waiting, or by acting as if it would not exist at all.

Field Note, Andean Latin America

And some of these kids are completely ostracized by the community and in some parts of the country, they are just thrown out in the bushes and left to die. Some people think they are demons. Some people think they have been bewitched.

Quote, Eastern Sub-Saharan Africa

Patients [are] unable to advocate for themselves. Field Note, Eastern Sub-Saharan Africa

Furthermore, the limited interaction between the community and the formal healthcare system is often characterised by hospitals with frequent electricity or supply outages, further contributing to perceptions of poor quality by word of mouth (Central Latin America, East Asia, Eastern sub-Saharan Africa). Finally, the most easily accessible and least costly providers in many of these communities are often the 'quacks' (South Asia), 'hakeems' (South Asia), 'shamans' (Central Latin America) and 'witch doctors' (Eastern sub-Saharan Africa). The result is that patients present late to the hospital, often with advanced or untreatable conditions.
By the time they get here, some could be dead, some could be in irreversible shock; some could have attained very gross morbidity.

Quote, Eastern Sub-Saharan Africa

So the families that can, come, and there are a lot of families that don't. We probably see about $25 \%$ of the new cases out there by ourselves...So if we're seeing 800 cases a year, there's probably another 2,500 that we don't see.

Quote, Eastern Sub-Saharan Africa

Some wait until they are literally bleeding to death.

Quote, South Asia

\section{THEME 2: ONCE PATIENTS REACH THE HOSPITAL, PROVIDERS FACE CRIPPLING DEFICITS IMPEDING PROVISION OF QUALITY CARE}

All participants agreed that the result was frequent absence of the tools necessary to deliver care. Many of the providers that we interviewed identified specific challenges in equipment maintenance. Since most equipment used in these settings is manufactured in the high-income environment, and it is either purchased by or donated to hospitals in these settings, the ability to service equipment locally is a core challenge.

Most of the equipment we get is on its last legs, and some of it gets broken here, and then you find the parent company. It's not manufacturing it anymore, and so you have equipment, but you can't even get the spare parts.

Transcript, Eastern Sub-Saharan Africa

Many public and rural facilities in low-resource settings lack operational blood banks. Where blood banks exist, low voluntary collection rates force a reliance on replacement blood donation in which families must donate on the spot or purchase from other facilities in exchange. A single unit of blood can cost as much as US \$150 (Southern sub-Saharan Africa).

Blood transfusion is one of the main problems...in both government and private [facilities]. We have access to a blood bank, but the family has to donate to get an exchange...if the family does not give, they cannot get.

Quote, Eastern Sub-Saharan Africa

[For] some operations that require a lot of blood, we have to get blood from a couple of blood banks.

Field Note, East Asia

We do not have a blood bank. We have a small laboratory, so if the patient needs blood, they have to tell their relatives or friends to give blood.

Field Note, Southeast Asia

Providers emphasised that facilities in low-resource settings serve large catchment populations, yet face workforce shortages that extend to a range of support staff, including nurses, administrative staff, researchers, translators, 
biomedical engineers and custodial staff. High patient volumes combined with severe workforce shortages lead to overcrowding. This is compounded by a shortage of beds in facilities, and leads to long waiting lists.

We just go with the flow...You can't do anything about this. There are only 300 surgeons in [the entire country]. My waiting list is more than one year. Some of them will die, some will get worse and more complicated, but that is life.

Quote, Eastern Sub-Saharan Africa

As a result, providers said that many patients face poor sanitation, heightened risk of infection and minimal, if any, privacy. 'Approximately two-thirds of all surgical patients will get infections', noted a rural surgeon in Western sub-Saharan Africa.

The hospital is not connected to centralized hot water, difficult to scrub with cold water (cold country!). We are not able to organize [and keep a] clean area separated from [the] infectious area, for example by... [separating patients in rooms] with infected wounds.

Field Note, Central Asia

Some you find sleeping under each other's beds, so they're trying to get space. This being a government facility...you never chase a patient out of a government facility.

Quote, Eastern Sub-Saharan Africa

Providers described hospitals operating over $300 \%$ of their capacity (Eastern sub-Saharan Africa), and with outpatient surgical clinics seeing upwards of 300 patients daily (South Asia).

\section{THEME 3: POLICIES AND REGULATIONS DO NOT REFLECT LOW-RESOURCE NEEDS}

Providers consistently voiced their frustration that, in addition to working within an underfunded health system, they are governed by policies that do not align with the realities of low-resource care provision. For example, some providers explained that their facilities' financial constraints are worsened by new government-implemented universal health coverage systems that mandate free care for children, pregnant women and the elderly (Southern sub-Saharan Africa, Western sub-Saharan Africa) but fail to provide hospitals with the resources to provide free care. They note that hospitals rely on government funding and suddenly declaring 'free' without a commensurate investment in hospitals does not actually translate to free care.

[Some of these policies are] like providing a patient with a free airline ticket where there is no airport.

Quote, South Asia

According to [the] government...you can't give blood unless you have a blood bank and this will cost at minimum 30 lakh rupees (about US\$60,000)...This is a huge deterrent for major surgery as emergency blood transfusion cannot be guaranteed.

Quote, South Asia

Many surgeons reported the need to work several jobs for financial stability; some have a private practice (Eastern sub-Saharan Africa, Western sub-Saharan Africa) or attend non-governmental organisation workshops (Southern sub-Saharan Africa) to make ends meet. In totality, providers note that existing policies fail to incentivise providers to work where they are most needed. Chronic underpayment and decrepit hospital infrastructure, minimal professional development opportunities, the isolation of practising largely alone and poor living conditions for families lower morale to serve in low-resource areas.

Many doctors and surgeons need to work in three or four places at once, and therefore are not $100 \%$ focused. Quote, Andean Latin America

...penniless recognition to the retired, and meager wages, which would force me to continue working after the age of 65. Field Note, Southern Latin America Currently, I am not getting paid for my work. Quote, Western Sub-Saharan Africa

So I say sometimes I regret why I did surgery. I'm like, if I had done public health maybe I would be better off...if my child asked me whether they should do surgery or not I think I would tell them to do something else.

Quote, Eastern Sub-Saharan Africa

Providers also noted that contextually inappropriate policies extend to professional standards and guidelines, including training systems, which are often blindly adopted from high-income environments. Oftentimes, trainees are not taught a generalist skill set but instead follow specialty designations irrelevant to the lowresource setting. One provider noted that his government restricts the number of neurosurgeons who can be trained, but does not allow generalists to perform lifesaving neurosurgical procedures (Southeast Asia). Providers explained that inadequate training can make surgeons and anaesthetists vulnerable to medical malpractice suits, sometimes without legal protection.

Sometimes we realize there is a gap between what should be taught, the standard, and what actually is taught because of what is available. So you need to take time to tell students, 'This is the standard, but here we are doing this.'

Quote, Eastern Sub-Saharan Africa

Teaching quality in medical schools is terrible. Professors spend five to ten percent [of their] time teaching. Residents learn from residents with poor supervision.

Field Note, South Asia There is a national lack of trained personnel, and too few training programmes.

Field Note, Southern Sub-Saharan Africa 
In some cases, needed policies do not exist. Providers widely noted the absence of system-wide coordination and interhospital communication channels, including transfer protocols. Patients face the consequences, both in the cost of transfer and the uncertainty in reaching definitive care.

In most [referral] cases, a private van has to be hired to transport patients...a stretcher with a mattress is placed inside...

Field Note, Andean Latin America

\section{THEME 4: PROVIDERS MAKE IT WORK DESPITE THE DEFICITS}

Interviewees across contexts relate practices used to overcome barriers to provision of surgical care. To combat public mistrust in the healthcare system, many providers describe engagement with the community through seminars in villages. One provider noted that he regularly meets with traditional healers to educate them on signs and symptoms of surgical emergencies (South Asia). Another noted that traditional midwives were being trained and given sterile equipment through a government programme so that they can improve safety of deliveries (Southern sub-Saharan Africa). Another gives community health workers his mobile number so that they can call to consult him about patient referrals (South Asia).

When ideal things are not always practical, try to make the practical things as ideal as possible.

Quote, South Asia

To make care affordable, providers note personally absorbing some expenses (Eastern sub-Saharan Africa, Southern Latin America, Southern sub-Saharan Africa) including purchasing materials (Southern Latin America) and providing care for a reduced or no charge. Some accept payment in kind (ie, maize, bananas, livestock). Some hospitals allow their patients to keep a 'checking account' to make small payments as they are able, while others allow patients to work in the hospital garden to cover their fees (Southern sub-Saharan Africa). A surgeon explained that the local church will donate a piglet to a patient needing nonurgent surgery, who can raise it and then sell it to pay for care (South Asia). To overcome geographical barriers, many hospitals try to provide accommodations, especially for pregnant women close to their delivery date. Furthermore, many providers arrange clinic days around local bus schedules, complete all diagnostics in a single day, and extend inpatient stays to accommodate suture removal in order to avoid repeated patient travel for follow-up visits (Eastern sub-Saharan Africa, South Asia, Western sub-Saharan Africa).

We pay out of our own [accounts for] patients all the time. I finance by running around the hospital, and buying them [supplies and medications] if I have to...
You ask family, you ask your friends who own companies to pay for an operation.

Quote, Eastern Sub-Saharan Africa

Surgical teams work with what they have. When there is no running water, they bring in buckets of water (Western sub-Saharan Africa). When the electricity goes out, back-up generators are employed. When generators fail or are absent, teams use torch lights or the light from a mobile phone (South Asia). Without ventilators, nurses and family members take turns manually ventilating patients (Eastern sub-Saharan Africa, South Asia, Western sub-Saharan Africa). Improvisation extends to equipment and supplies where single-use materials are frequently resterilised for repeated use. One surgical team created a 'cholovac', a Foley catheter connected to a $20 \mathrm{cc}$ syringe to simulate the drainage of a Hemovac (Andean Latin America). Frustrated by the price of a hand sanitiser on the international market, one facility makes its own sanitiser using alcohol from a local distillery (South Asia). Many providers use mosquito net material instead of expensive, synthetic hernia meshes for hernia repairs (South Asia).

I have taken maybe 5 years without seeing a cord clamp and the babies are delivered every day. So you definitely have to improvise. And the rib of a glove is a very important thing. And I think if the manufacturer of the gloves knew that the rib is used for tying that cord of the baby, maybe they would even increase the price [laughter].

Quote, Eastern Sub-Saharan Africa

Stretched very thin, physicians and nurses share responsibilities. They also recruit community members, and train them internally to facilitate a range of clinical and non-clinical tasks. Most staff is trained on the job, given the absence of training programmes that prepare trainees for the broad experience that low-resource providers can expect to encounter. Many providers take on significant risk to care for their patients, sometimes jeopardising their own safety. A surgeon in Eastern sub-Saharan Africa noted wearing a single glove despite infection risks, and another provider in the same region described donating his own blood in order to obtain a replacement donation for his patient.

If you [the surgeon] can't get blood, you can drive to the blood bank and donate your own blood, and then drive it back to your patient. We have done that on many occasions.

Quote, Eastern Sub-Saharan Africa

Still, workarounds are not long-term solutions and providers are well aware of their limits.

We give priority to the sickest patients. Sometimes, the problem is we run out of sterile drapes. The washing machine or sterilizer is not working, and then we would have to refer the patient somewhere else.

Quote, Eastern Sub-Saharan Africa 


\section{DISCUSSION}

This manuscript represents the voices of providers on the front line of surgical care delivery in some of the world's poorest areas. While urban surgical teams described overcrowding in hospitals with limited clinical support and administrative leadership, rural providers reported working in a facility without basic infrastructure, compounded by shortages of equipment, consumables and banked blood. Participants across settings articulated pervasive workforce shortages and concerns with national health policies that, without local context, hinder their ability to provide care. Despite difficult settings and trying circumstances, these providers actively battle the challenges associated with weak health systems on a daily basis.

It is no surprise then that their perceptions of challenges in their health systems align well with prior global literature that also aimed to characterise health systems in low-resource settings. Patients often do not seek, reach or receive care because they are poor $^{13}$ and fear that surgery will push them further into poverty. ${ }^{14}$ In most low-resource settings, out-of-pocket payments for surgical care predominate, ${ }^{15}$ and perpetuate the 'poverty trap'. ${ }^{15-}$

${ }^{17}$ Even free care may not ensure equity since it does not address cultural barriers ${ }^{18}$ or the indirect costs associated with care, which can be substantial. ${ }^{19}$ If patients do reach care, they often face hospitals that are underfunded and ill equipped to serve them. ${ }^{2}{ }^{4}$ Survey data from the WHO have echoed the themes recounted by our providers: $22 \%$ of hospitals surveyed in low-income countries were without running water, $24 \%$ without oxygen supply and $31 \%$ without consistent electricity. ${ }^{20}$ Hospitals commonly have stock-outs of consumables, ${ }^{21} 22$ and limited equipment, most of which is donated, often not in working condition. ${ }^{23}$ Shortages of equipment and workforce are especially prominent in primary hospitals, and push tertiary facilities beyond their capacity, ${ }^{24}$ creating long waiting lists for surgical cases, ${ }^{25}$ and leading to additional stress, professional burnout and a profound sense of isolation among providers.

Our study shows, however, that while these obstacles are not novel or surprising-and in many cases may take decades to surmount-local providers are already implementing contextually appropriate short-term and medium-term solutions. ${ }^{26-28}$ They have found that not all problems and all solutions require large amounts of funding; as Boozary et $a l^{29}$ concluded, 'safer, more effective and more respectful care need not be more expensive'. Where patients are particularly poor, clever workarounds help make care more affordable or free (eg, accepting payment-in-kind) or more reachable to patients who travel from far away (eg, scheduling clinics around public transportation times to allow for same-day diagnosis and treatment). Where supplies are limited or unavailable, inexpensive local alternatives are fashioned to fill the need gap (eg, sterilised mosquito net for hernia repair, ${ }^{30-36}$ a cystoscope for diagnostic laparoscopy, ${ }^{37-39}$ gasless laparoscopy ${ }^{40}$ ). Given the broad variation in how governments and policymakers have approached these issues over the years, local clinicians steeped in these clinical environments have the best sense of what their patients are experiencing and how they can provide better care.

Ironically, and unfortunately, despite having the best understanding of the challenges in low-resource care provision, these individuals are typically left out of the published literature and global initiatives, largely because they are unable or unwilling to leave their patients behind in order to attend a national meeting or international forum. Some are the sole providers of care within a catchment area that extends hundreds of kilometres. Many of these providers do not speak English.

As such, given the commonalities across settings in the long-standing challenges in care delivery, ${ }^{41}$ the scale-up of surgical infrastructure, ${ }^{25}$ workforce ${ }^{5} 6$ and financial protection $^{42}$ is supported across settings by recommendations endorsed by international fora. ${ }^{2} 43-45$ Progress on these solutions may leverage existing global health advances, ${ }^{46} 47$ but may be slow, as construction of facilities and training of a workforce require time. Many of these are decisions that will require years of consensus building and political prioritisation ${ }^{48}$ in the shift of surgery from the 'neglected stepchild' of global health ${ }^{49}$ to an 'indivisible, indispensable part of healthcare'. 50 Financing for these efforts will require long-term commitments, substantial mobilisation of domestic resources, and continued global philanthropy. ${ }^{75} 52$ More immediate solutions will be found, however, in following the lead of providers. These individuals have already shown an ability across culture and context to make care available by minor but timely process improvements and alterations-changes that may be most impactful in reducing in-hospital delays. ${ }^{53}$ These individuals should be celebrated rather than neglected, and their input actively sought as health systems strengthening requires input from the most relevant stakeholders in a health system: providers and their patients. ${ }^{42}$

There are several limitations to this study. While interviewers were trained with an implementation manual to standardise their interviews, bias may have been introduced by differences between the interviewer and interviewee in the native language, demographic and educational background, or status within the medical profession hierarchy. Logistically, interviewers were able to reach more participants in some countries than in others, and the length and detail of responses given varied based on how much time each interviewee could give to participate. There was some variation in data preparation by the interviewer (eg, method of transcription, field notes and translation) that may have introduced variation in how data were coded. Settings were included if they were considered to be 'low-resource', which we defined as an area that lacks the necessities for basic healthcare, but this is not a homogeneous categorisation. While rural and urban providers were overall represented equally, skewed ratios existed in individual 
countries, and most participants were male; this unequal distribution may have introduced bias, but some of this reflects the imbalances in global surgical workforce distribution $^{23}$ and gender inequity. Related to this imbalance, while reputational case selection is a widely used qualitative research methodology that allows high-yield identification of individuals with relevant input into the study, ${ }^{10}$ it may result in a disproportionate number of interviewees with similar experiences. De-identification prior to data analysis and the large number of participants helped to minimise bias.

While a strength of this study is that it offers new data from front-line surgical providers, it is also limited to that perspective, and presents the need for replicating these efforts with other types of providers, as well as patient populations and policymakers. While our study revealed the commonalities in challenges across setting, specific focus on the differences and variations in care provision may provide an even further understanding on how surgical care can be practised safely and effectively across the world. Further interrogation into the solutions and workarounds may reveal opportunities to scale more quickly and yield lessons and process improvements for the high-income setting.

In summary, this study illustrates the shared challenges faced by surgical providers in low-resource settings, as well as the striking frequency and ingenuity with which individual providers devise workarounds to these challenges. While these findings improve our understanding of the landscape of surgical care provision worldwide and suggest ways in which international organisations and local governments can support providers and strengthen surgical systems, they also highlight the primacy of local stakeholder input and involvement in national surgical planning processes. ${ }^{54}$

\footnotetext{
Author affiliations

${ }^{1}$ Program in Global Surgery and Social Change, Harvard Medical School, Boston, Massachusetts, USA

${ }^{2}$ Beth Israel Deaconess Medical Center, Boston, Massachusetts, USA

${ }^{3}$ Boston Children's Hospital, Boston, Massachusetts, USA

${ }^{4}$ Harvard Medical School, Boston, Massachusetts, USA

${ }^{5}$ Alpert Medical School, Brown University, Providence, Rhode Island, USA

${ }^{6}$ Harvard T. H. Chan School of Public Health, Boston, Massachusetts, USA

${ }^{7}$ Medical College of Wisconsin, Milwaukee, Wisconsin, USA

${ }^{8}$ University of Washington, Seattle, Washington, USA

${ }^{9}$ Partners in Health, Boston, Massachusetts, USA

${ }^{10}$ Brigham and Women's Hospital, Division of Global Health Equity, Boston, Massachusetts, USA

${ }^{11}$ BARC Hospital (Government of India), HBNI University, Mumbai,

Maharashtra, India

${ }^{12}$ Health Systems and Policy Research Group, Department of Public Health

Sciences, Karolinska Institutet, Stockholm, Sweden
}

\section{Handling editor Valery Ridde.}

Twitter Nakul Raykar @NakulRaykar, Rachel Yorlets @RachelYorlets, Charles Liu @chasliu, Sarah Greenberg @SLMGreenberg, Meera Kotagal @mkotagal, John Meara @JohnMeara, Nobhojit Roy @nobsroy, and Rowan Gillies @rogillies.

Acknowledgements This study would not have been possible without all of the surgical teams who worked tirelessly to provide care. The authors especially thank all of those who coordinated and collected data for this project: Nivaldo Alonso, Zara Ansari, Paul Arkell, Bilguun Beck, Adebe Bekele, Luis Bermudez, Heather Bougard, Gloria Boye, Sule Burger, Isabelle Citron, Damian Clarke, Miliard Derbew, Christopher Doiron, Shenaaz El-Halabi, Rafael Galli, Timothy Hardcastle, Caitrin Kelly, Jong Hun Kim, Francis Lai, Christopher Lavy, Tonatiuh Lievano, Ganbold Lundeg, Laura Luque, Dimple Mirchandani, Saba Morshed, Sherry Prasad, Gaboelwe Rammekwa, Johanna N Riesel, Edgar Rodas ${ }^{\ddagger}$, Sakib Rokadiya, Lubna Samad, Camilo Sepulveda, Alireza Shirazian, Martin Smith, Alexandra George Smith, Lucas Sobrado, Bin Song and Nichole Starr. ${ }^{\ddagger}$ Deceased.

Contributors NPR contributed to the conception of the study and the study design, created the interview guide, implementation manual and coding manual, trained interviewers, collected, analysed and interpreted data, and wrote the manuscript. RRY created the coding manual and figures, analysed and interpreted data, conducted a literature search, and contributed to the writing. CL coordinated data collection across countries, and communicated with interviewers. RG contributed to the study design and methodology, and data interpretation. SLMG, MK and PEF contributed to the conception of the study. JGM, NR and RDG contributed to the conception of the study and study design. All authors contributed to revisions and approved the final manuscript.

\section{Competing interests None declared.}

Ethics approval This study was confirmed to be exempt from review by the Institutional Review Board at Boston Children's Hospital in Boston, Massachusetts, USA.

Provenance and peer review Not commissioned; externally peer reviewed.

Data sharing statement The authors have represented, in varying levels of detail, the majority of the qualitative data that we collected for this study, and do not have unpublished data that are publicly available.

Open Access This is an Open Access article distributed in accordance with the Creative Commons Attribution Non Commercial (CC BY-NC 4.0) license, which permits others to distribute, remix, adapt, build upon this work noncommercially, and license their derivative works on different terms, provided the original work is properly cited and the use is non-commercial. See: http:// creativecommons.org/licenses/by-nc/4.0/

\section{REFERENCES}

1. Shrime MG, Bickler SW, Alkire BC, et al. Global burden of surgical disease: an estimation from the provider perspective. Lancet Glob Health 2015;3:S8-9.

2. Meara JG, Leather AJM, Hagander L, et al. Global Surgery 2030 evidence and solutions for achieving health, welfare, and economic development. Lancet 2015;386:569-624.

3. Alkire BC, Raykar NP Shrime MG et al. Global access to surgica care: a modelling study. Lancet Glob Health 2015;3:e316-23.

4. Milsom P, Mukhopadhyay S, Federspiel F, et al. Appendix 2.3: infrastructure literature review of Global Surgery 2030: evidence and solutions for achieving health, welfare, and economic development. Lancet 2015;386:569-624.

5. Dubowitz G, Detlefs S, McQueen KA. Global anesthesia workforce crisis: a preliminary survey revealing shortages contributing to undesirable outcomes and unsafe practices. World J Surg 2010;34:438-44.

6. Holmer $\mathrm{H}$, Lantz A, Kenjumen $\mathrm{T}$, et al. Global distribution of surgeons, anaesthesiologists, and obstetricians. Lancet Glob Health 2015;3:S9-11.

7. Jamison DT, Summers LH, Alleyne G, et al. Global health 2035: a world converging within a generation. Lancet 2013;382:1898-955.

8. Bernard HR. Social research methods: qualitative and quantitative approaches. Thousand Oaks: Sage Publications, 2000.

9. Rubin HJ, Rubin IS. Qualitative interviewing: the art of hearing data. Thousand Oaks: Sage Publications, 1995.

10. Miles MB, Huberman AM. Qualitative data analysis: an expanded sourcebook. Thousand Oaks: SAGE, 1994.

11. Crabtree BF, Miller WL. Doing qualitative research. Thousand Oaks: Sage Publications, 1999.

12. Murray CJ, Vos T, Lozano R, et al. Disability-adjusted life years (DALYs) for 291 diseases and injuries in 21 regions, 1990-2010: a systematic analysis for the Global Burden of Disease Study 2010. Lancet 2013;380:2197-223.

13. Grimes CE, Bowman KG, Dodgion CM, et al. Systematic review of barriers to surgical care in low-income and middle-income countries. World J Surg 2011;35:941-50. 
14. Shrime MG, Dare AJ, Alkire BC, et al. Catastrophic expenditure to pay for surgery: a modelling study. Lancet Glob Health 2015;3(Suppl 2):S38-44.

15. Scheiber GJ, Gottret P, Fleisher LK, et al. Financing global health: Mission unaccomplished. Health Aff 2007;26:921-34.

16. Azariadis $C$. The Theory of Poverty Traps. What have we learned? In: Bowles S, Durlauf SN, Hoff K, eds. Poverty Traps. Princeton: Princeton University Press, 2006;17-40.

17. Sachs J. Macroeconomics and health: investing in health for economic development, Executive Summary of Report of the Commission on Macroeconomics and Health. WHO. 2001 (cited 10 Oct 2015). http:// www.who.int/macrohealth/action/sintesis15novingles.pdf

18. Groen RS, Sriram VM, Kamara TB, et al. Individual and community perceptions of surgical care in Sierra Leone. Trop Med Int Health 2014:19:107-16.

19. Matousek AC, Matousek SB, Addington SR, et al. The struggle for equity: an examination of surgical services at two NGO hospitals in rural Haiti. World J Surg 2015;39:2191-7.

20. O'Neill K, Daniels KM, Greenberg SLM, et al. Appendix 2.2: situational analysis tool for Global Surgery 2030: evidence and solutions for achieving health, welfare, and economic development. Lancet 2015;386:569-624.

21. Ahmed SM, Evans TG, Standing $\mathrm{H}$, et al. Harnessing pluralism for better health in Bangladesh. Lancet 2013;382:1746-55.

22. Gallien J, Rashkova I, Atun RA, et al. National drug stockout risks in Africa: analysis of the global fund disbursement process for procurement from 2002 to 2013. Ross School of Business Working Paper, Number 1241. May, 2014.

23. Perry LMalkin R. Effectiveness of medical equipment donations to improve health systems: how much medical equipment is broken in the developing world? Med Biol Eng Comput 2011;49:719-22.

24. Rehmani R. Emergency section and overcrowding in a university hospital of Karachi, Pakistan. J Pak Med Assoc 2004:54:233-7.

25. Grimes C, Law R, Borgstein E, et al. Systematic review of met and unmet need of surgical disease in rural Sub-Saharan Africa. World J Surg 2011;36:8-23.

26. Ronsmans C, Holtz S, Stanton C. Socioeconomic differentials in caesarean rates in developing countries: a retrospective analysis. Lancet 2006;368:1516-23.

27. Rose J, Weiser TG, Hider P, et al. Estimated need for surgery worldwide based on prevalence of diseases: a modelling strategy for the WHO Global Health Estimate. Lancet Glob Health 2015;3(Suppl 2):S13-20.

28. Zafar SN, Fatmi Z, lqbal A, et al. Disparities in access to surgical care within a lower income country: an alarming inequity. World J Surg 2013;37:1470-7.

29. Boozary AS, Farmer PE, Jha AK. The ebola outbreak, fragile health systems, and quality as a cure. JAMA 2014;312:1859-60.

30. Lofgren J, Nordin P, Ibingira C, et al. A randomized trial of low-cost mesh in groin hernia repair. N Engl J Med 2016;374:146-53.

31. Tongaonkar RR, Reddy BV, Mehta VK, et al. Preliminary multicentric trial of cheap indigenous mosquito-net cloth for tension-free hernia repair. South Asian J Surg 2003;65:89-95.

32. Clarke MG, Oppong C, Simmermacher R, et al. The use of sterilised polyester mosquito net mesh for inguinal hernia repair in Ghana. Hernia 2009;13:155-9.
33. Sanders DL, Kingsnorth AN, Stephenson BM. Mosquito net mesh for abdominal wall hernioplasty: a comparison of material characteristics with commercial prosthetics. World J Surg 2013;37:737-45.

34. Sørensen CG, Rosenberg J. The use of sterilized mosquito nets for hernioplasty: a systematic review. Hernia 2012;16:621-5.

35. Shillcutt SD, Clarke MG, Kingsnorth AN. Cost-effectiveness of groin hernia surgery in the Western Region of Ghana. Arch Surg 2010;145:954-61.

36. Shillcutt SD, Sanders DL, Teresa Butrón-Vila M, et al. Cost-effectiveness of inguinal hernia surgery in northwestern Ecuador. World J Surg 2013;37:32-41.

37. Gnanaraj J. Diagnostic laparoscopies in rural areas: a different use for the cystoscope. Trop Doct 2010;40:156.

38. Chao TE, Mandigo M, Opoku-Anane J, et al. Systematic review of laparoscopic surgery in low- and middle-income countries: benefits, challenges, and strategies. Surg Endosc 2016;30:1-10.

39. Udwadia TE. Diagnostic laparoscopy. Surg Endosc 2004;18:6-10.

40. Gnanaraj J, Rhodes M. Laparoscopic surgery in middle- and low-income countries: gasless lift laparoscopic surgery. Surg Endosc 2016;30:2151-4.

41. Ledesma CL, Hughes TG, Pellegrini CA, et al. Rural surgery is a global issue: the perspective of an Argentine surgeon. ACS Bulletin. 2014 (cited 10 Oct 2015). http://bulletin.facs.org/2014/04/ruralsurgery-is-a-global-issue-the-perspective-of-an-argentine-surgeon/

42. Bump JB, Cashin C, Chalkidou K, et al. Implementing pro-poor universal health coverage. Lancet Glob Health 2016;4:e14-16.

43. Debas Haile T, Peter D, Atul G, et al. Disease control priorities. 3rd edn. Vol 1. Essential surgery. Washington DC: World Bank, 2015. https://openknowledge.worldbank.org/handle/10986/21568 License: CC BY 3.0 IGO

44. WHA. WHA 68.15. Strengthening emergency and essential surgical care and anaesthesia as a component of universal health coverage. Geneva, Switzerland: World Health Association, 2015

45. The World Bank. World Development Indicators. 2015. http://data. worldbank.org/indicator/SH.XPD.PCAP

46. Millennium Development Goals (MDGs) [Internet]. World Health Organization. 2016 (cited 18 July 2016). http://www.who.int/ mediacentre/factsheets/fs290/en/

47. Farmer P, Kim J, Kleinman A, et al. Reimagining global health Berkeley: University of California Press, 2013.

48. Dare AJ, Lee KC, Bleicher $\mathrm{J}$, et al. Prioritizing surgical care in national health agendas: a qualitative case study of Papua New Guinea, Uganda, and Sierra Leone. PLoS Med 2016;13:e1002023.

49. Farmer PE, Kim JY. Surgery and global health: a view from beyond the OR. World J Surg 2008;32:533-6.

50. Kim J. Opening address: the North American launch of the Lancet Commission on Global Surgery. Boston, USA, 2015.

51. Brugha R, Donoghue M, Starling M, et al. The Global Fund: managing great expectations. Lancet 2004;364:95-100.

52. Yang A, Farmer PE, McGahan AM. 'Sustainability' in global health Glob Public Health 2010;5:129-35. Abstract only.

53. Kumar V, Khajanchi M, Raykar NP, et al. Waiting at the hospital door: a prospective, multicenter assessment of third delay in four tertiary hospitals in South Asia. Lancet 2015;385(Suppl 2):S24.

54. Ng-Kamstra JS, Greenberg SL, Abdullah F, et al. Global Surgery 2030: a roadmap for high income country actors. BMJ Global Health 2016;1:e000011. 